\title{
The value of ultrasonogram in the diagnosis of ovarian dermoid cysts
}

Pradhan S

Sujan Pradhan, Lecturer, Department of Radiology, Nepal Medical College Teaching Hospital, Jorpati, Kathmandu, Nepal.

\section{Abstract}

Mature cystic teratoma often referred to as dermoid cysts have been diagnosed using all imaging modalities. Dermoid cysts present various and complex ultrasonographic aspects. At times diagnosis may be difficult and lead to confusion due to its complex solid and cystic nature. The specificity for diagnosis of fat and calcification makes computed tomography (CT) scan the modality of choice. But CT scan is high technique equipment, expensive and may not be affordable or available at all places. Advances in the quality of USG machines, better experiences of ultrasound operators and thorough analysis of all ultrasound features that characterise dermoid cysts have resulted in an increased accuracy of exact ultrasonographic diagnosis of dermoid cysts in the vast majority of the cases and now used as the first preoperative work-up method of choice for the assessment of adnexal masses in clinical practices.

Key words: Dermoid cyst, mature cystic teratoma, ultrasonography

\section{INTRODUCTION}

$\mathrm{G}$ erm cell tumours constitute $15-20 \%$ of ovarian tumours and majority of them are mature cystic teratoma, commonly called dermoid cyst and they are benign neoplasms'. Dermoid cysts originate in the pluripotent germ cells. They form from a single germ cell after the first meiotic division ${ }^{2}$. They are composed of well-differentiated tissues of at least two of the three germ layers (ectoderm, mesoderm and endoderm). They always contain mature ectodermal tissue (skin, brain). In over $90 \%$ of cases they contain mesodermal tissues (muscles, fat, bone, cartilage) and endodermal tissues (ciliated, gastrointestinal mucinous or bronchial epithelium and thyroid tissues) $)^{3,4}$. On the surface, dermoid cysts are covered by compressed ovarian stroma, usually hyalinised. The cyst wall is made of squamous epithelium. In this epithelium, hair follicles, sweat glands, muscles and other tissues can be found. Inside the cyst there can be fat, sebaceous secretion, hair follicles, hair and in about $30 \%$ of cases organ like structure (teeth, bone fragments) ${ }^{5}$. Dermoid cysts have been reported in patients of one to 91 years with peak incidence between 20-30 years of age ${ }^{6,7}$. Twenty percent

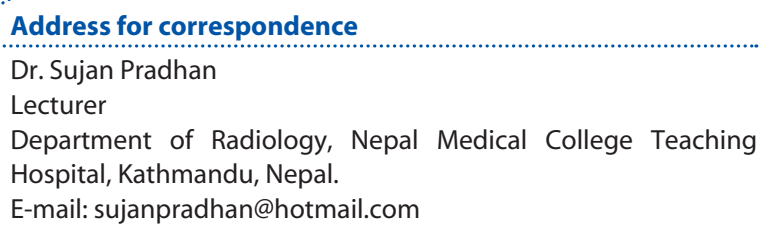

are seen in the post-menopausal periods ${ }^{8}$. Ovarian dermoid cysts are also the most frequently encountered ovarian tumours in children ${ }^{9}$. It is observed that mature cystic teratomas can show recurrence at the rate of three to four percent and the recurrence rate is higher in the patients who are younger at the time of first diagnosis ${ }^{10}$. At the same time, bilaterality and multilocularity are observed more often in the recurrent cases $^{10}$. The size of dermoid cysts may be extremely variable. They can be found accidentally when they measure just around one $\mathrm{cm}$ and are situated inside the ovary without causing ovarian distortion (Figure 1). They can also have gigantic dimension of $40 \mathrm{~cm}$ or more (Figure 2). Usually when they are diagnosed, dermoid cysts measure less than $10 \mathrm{~cm}$ and most of the time they are asymptomatic. The tumours are usually unilateral but in $10-15 \%$ of the cases they are bilateral ${ }^{10}$ (Figure 3). The dermoid cysts have a slow growth rate of $1.8 \mathrm{~mm} /$ year, that is why some authors recommend a non-surgical management if the size is not over six $\mathrm{cm}^{11}$. The mature cystic teratoma are often pediculate and because of their rich fat content, dermoid cysts are frequently situated superior to the uterine fundus and often complicated by torsion ${ }^{12,13}$. Dermoid cysts have been diagnosed using all imaging modalities. Ultrasonogram has increasingly been used for the assessment of women with adnexal masses which consequently lead to exact diagnosis of ovarian abnormalities. 


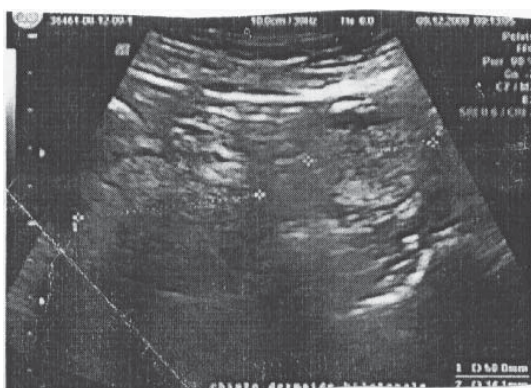

Figure 1: Bilateral dermoid cysts.

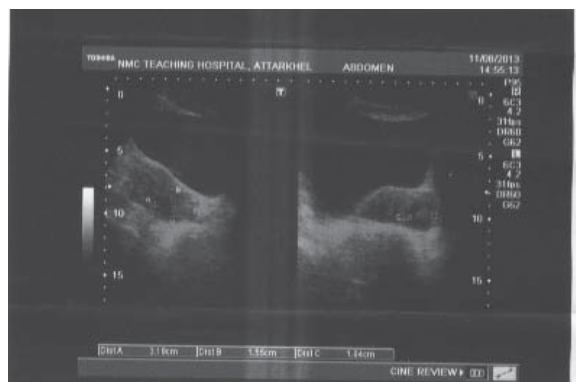

Figure 2: Hyperechoeic small ovarian dermoid cyst.

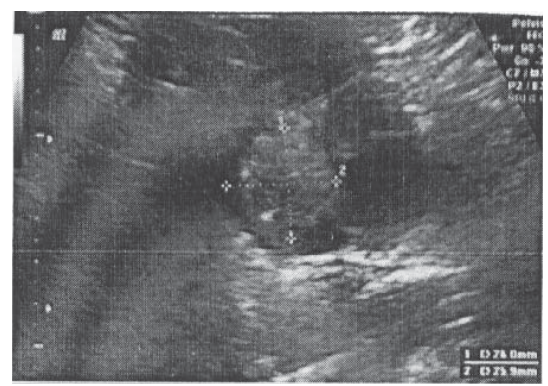

Figure 3: Hyperechoeic, small ovarian dermoid cyst. Near the cyst is an ovarian follicle.
The purpose of this paper is to present the various characteristics features of dermoid cysts in USG pictorial form since USG has an established role in the evaluation of dermoid cysts in the clinical practices.

\section{BODY}

The mature cystic teratomas have a classical radiographic and ultrasonographic gray-scale morphological features which can lead to an exact diagnosis in the vast majority of the cases ${ }^{\text {s. But }}$ at times benign cystic teratoma may appear to be suspiciously malignant during initial scan due to its complex solid and cystic nature ${ }^{16-19}$. The malignant degeneration may be present in one to three percent of all cystic teratomas ${ }^{16-26}$. Computed Tomography (CT) scan, specifically diagnoses fat, calcifications and fat level correctly and is considered the modality of choice. The CT scan however is high technique equipment, expensive, and may not be available or affordable at all places. Advances in the quality of ultrasound equipment and better experiences of ultrasound operators have resulted in an increased accuracy of ultrasound diagnosis of dermoid cysts in the vast majority of the cases. Transvaginal ultrasound has an established role in the evaluation of adnexal masses and provides an accurate assessment of ovarian morphology and is now used as the first pre-operative work-up method of choice for the assessment of adnexal masses in clinical practice ${ }^{15}$. The most classical ultrasonographic appearances of dermoid cysts are:

\section{The dermoid plug: Rokitanski nodule}

It is probably the most characteristic aspect of the dermoid $\mathrm{cyst}^{27,28}$. A nodular prominence is usually present in the wall of the cyst at the junction between the teratoma and the normal ovarian tissue and this has been called a Rokitanski protuberance $\mathrm{e}^{20,27,28}$. It consists of nodular, pediculate, dense, parietal structure that forms on the cyst interior surface and bulges inside it ${ }^{4}$. The greatest cellular activity is found in this area and may contain bone, teeth, hair that can extend into the cyst cavity ${ }^{27,28}$. A dermoid cyst may contain one or more Rokitanski nodules and because of its greatest cellular activity, it should be sampled thoroughly to rule out malignant components $17,21,27,28$. The ultrasound appearance is that of an hyperechoic nodular structure, usually the distal acoustic shadow, situated near the cyst wall (Figure 4-9) 4,12,29. The shadowing may be caused by a calcification or by a sebum and hair conglomerate $e^{4,12,28}$. After puberty both Rokitansky nodule and the acoustic shadow appear in over $70 \%$ of the cases $^{12}$. Before puberty the echoic nodule appears in about $40 \%$ of the cases and the acoustic shadow in only $15 \%$ of the dermoid cysts $^{12}$. The dermoid plug may be found as a single manifestation of a dermoid cyst in $16 \%$ of the cases $^{20,28}$.

\section{Dermoid mesh:}

The dermoid mesh corresponds to the hair present inside the cyst. The ultrasonographic appearance may be that of a long, echoic lines or that of point-like echoic images inside the lesion depending on the view (Figure $10-13)^{4,20,28}$. The fibrin threads inside the haemorrhagic cyst could mimic this aspect. But only in one percent of the cases this finding appears isolated without being accompanied by other signs characteristic to dermoid cyst ${ }^{20}$.

\section{Tip of iceberg sign:}

In some cases only the contour of the cyst may be seen because of the distal acoustic shadow. In these circumstances an accurate measurement of the cyst is difficult or impossible to determine (Figure 14, 15). There are three types of tissues that can produce acoustic shadowing: calcified structures (bone, teeth), hair conglomerates inside the cyst cavity and the fat within the Rokitanski nodule ${ }^{28,29}$. In $16 \%$ of the cases this sign is the only ultrasonographic manifestation of a dermoid cyst $^{20}$. The acoustic shadowing given by the hyperechogenicity of the structures inside the cyst may be diffuse if it involves the whole cyst or it may be 
limited to a part of the cyst. Only eight percent of the dermoid cysts contain hyperechoic structures without distal shadow ${ }^{12}$.

\section{Sedimentation}

Sometimes a tendency towards sedimentation occurs within the serous component of the dermoid cyst and sebum, producing an ultrasound visible interface that changes position with gravity (Figure 16, 17) ${ }^{13,30}$. A fluid-fluid level within an adnexal mass does not have diagnostic value for a dermoid cyst. This finding must be interpreted to context of other associated criteria ${ }^{20}$.

\section{The echoic "white ball":}

The echoic "white ball" aspect may occupy sometimes the entire cystic cavity (Figure 18). The histopathologic examination of the entire echoic dermoid cyst shows mainly hair, fat and sebaceous materials ${ }^{4,31}$. At other times, an echoic, relatively homogenous and lobulated mass that fills a part of the cyst cavity is visualized (Figure 19). Sometime echoic spheres produced by fat material conglomerate that float inside the cyst may be seen within a dermoid cyst (Figure 20, 22, 23). They do not present acoustic shadow or a tendency towards sedimentation $^{32}$.
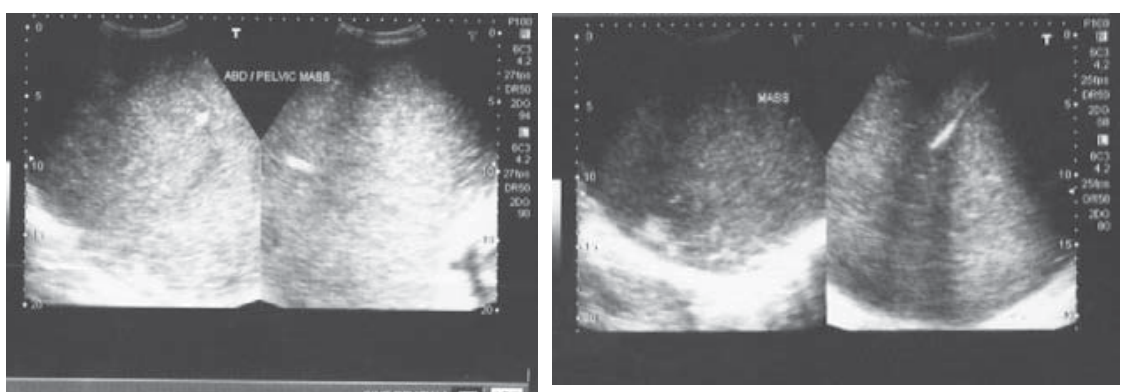

Figure 4: Panoramic view of a gigantic Figure 5: A huge dermoid cyst. dermoid cyst measuring $40 \mathrm{~cm}$.

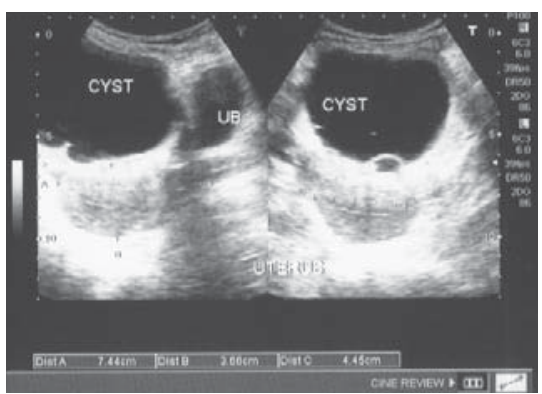

Figure 7: Rokitanski Nodule

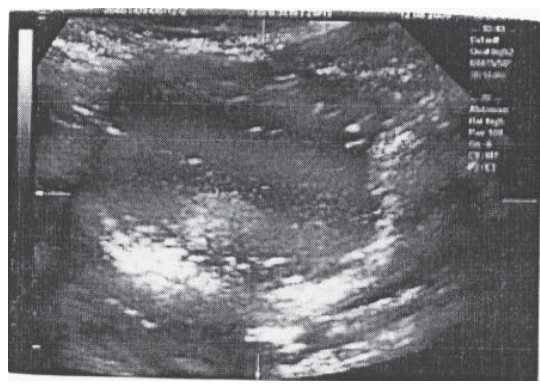

Figure 10: Dermoid Mesh

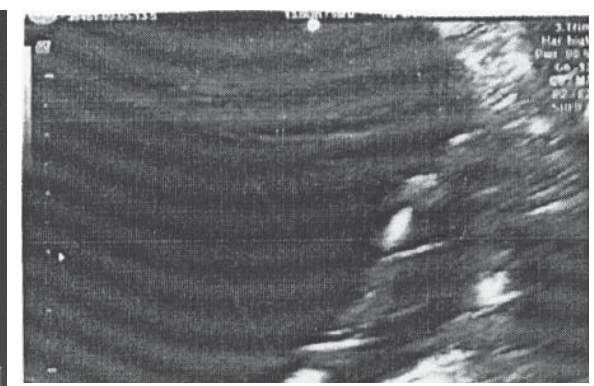

Figure 8: Dermoid Mesh with fine barely visible lines emerging from the Rokitanski Nodule.

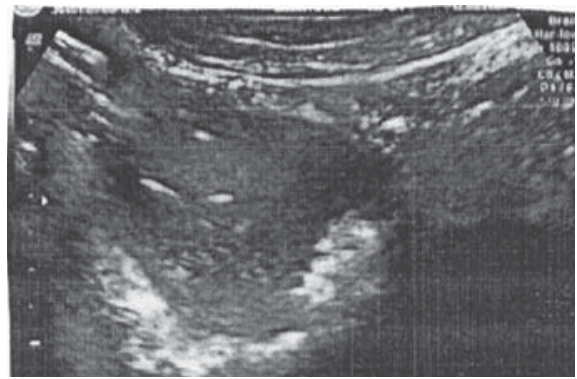

Figure 11: Hyperechoeic lines produced by presence of hairs.

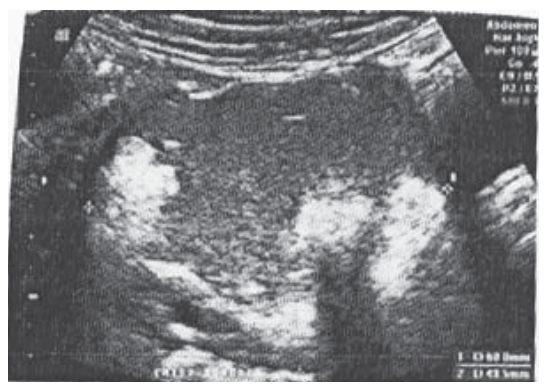

Figure 6: Rokitanski Nodule inside a complex dermoid cyst.

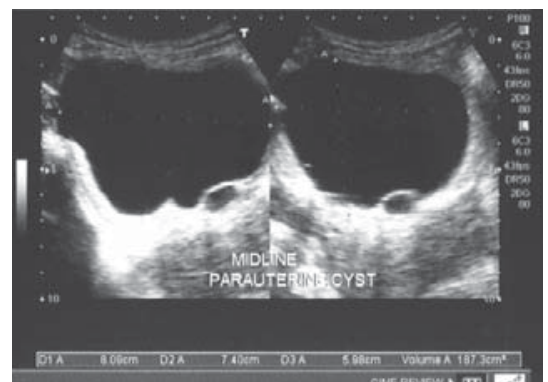

Figure 9: Dermoid cyst with Rokitanski Nodule.

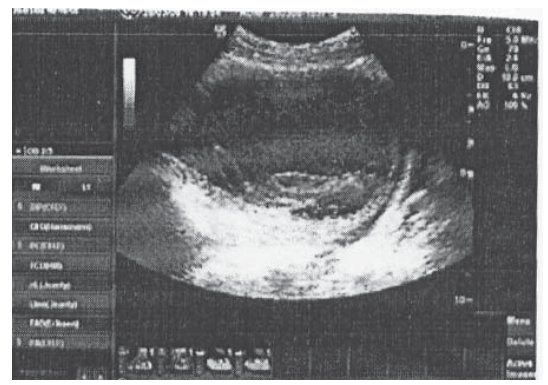

Figure 12: Fine long echoic lines in a dermoid cyst. 


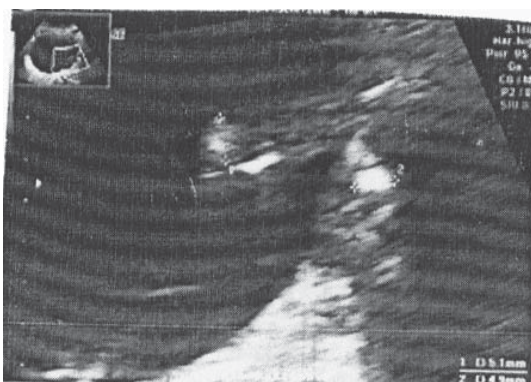

Figure 13: Calcification in a dermoid Figure 14: The tip of the iceberg sign. plug.
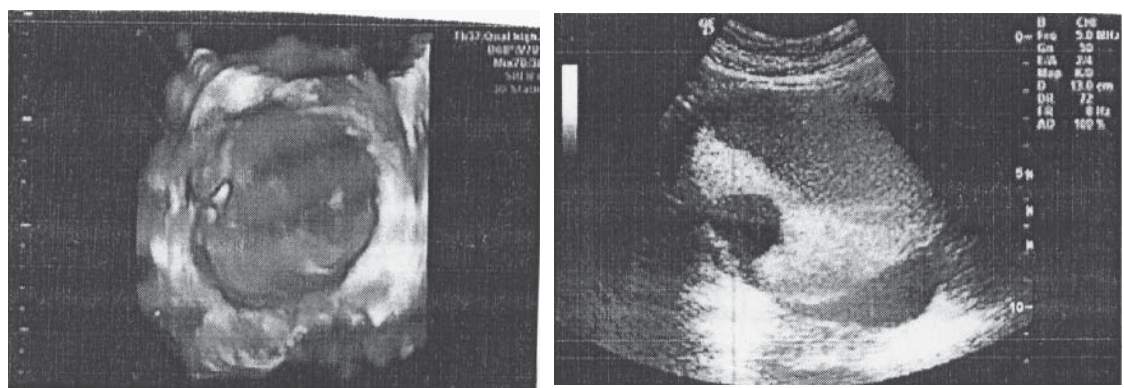

Figure 16: Tooth inside the dermoid Figure 17: Fluid - fluid level insid the plug.
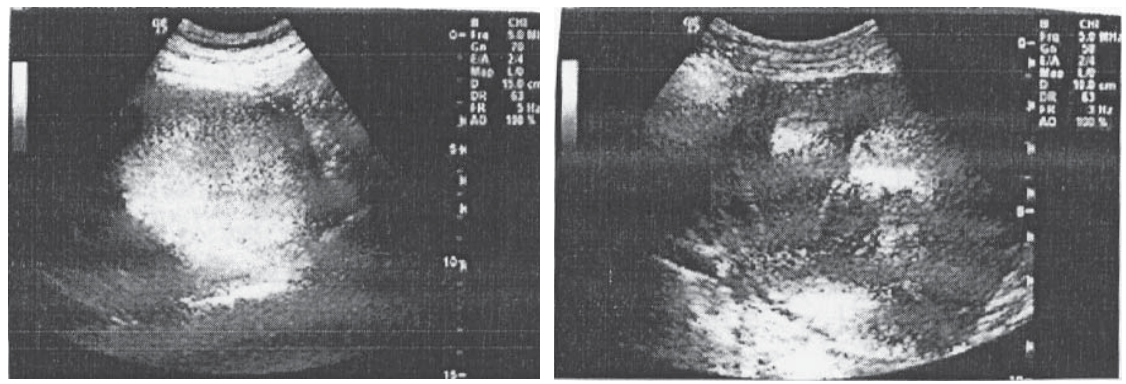

Figure 19: The echoeic white ball filling Figure 20: Adipose material spheres the whole cystic cavity.

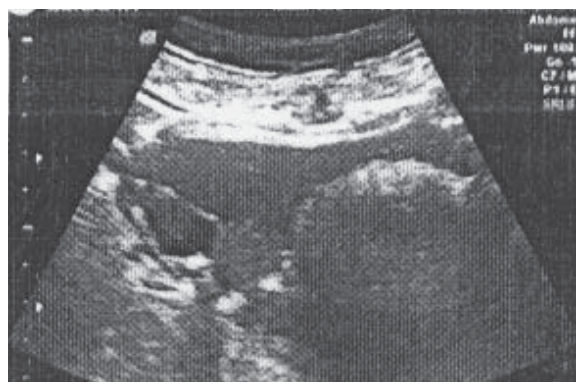

Figure 15: Calcification within dermoid cyst.

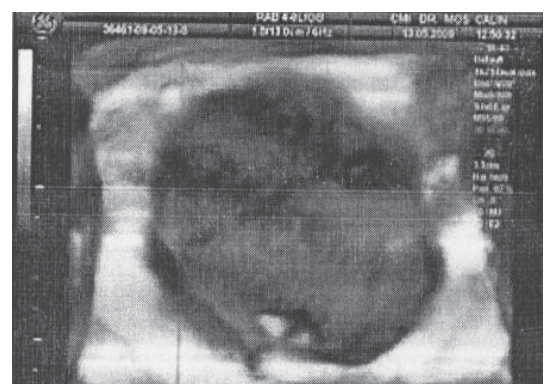

Figure 18: Dermoid cyst with fluid-fluid level.

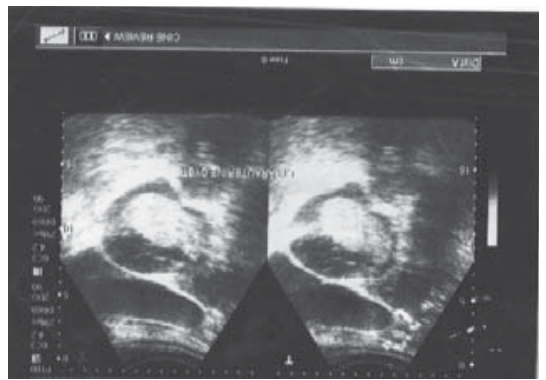

Figure 21: Adipose material spheres showing floating fat ball within the dermoid cyst.

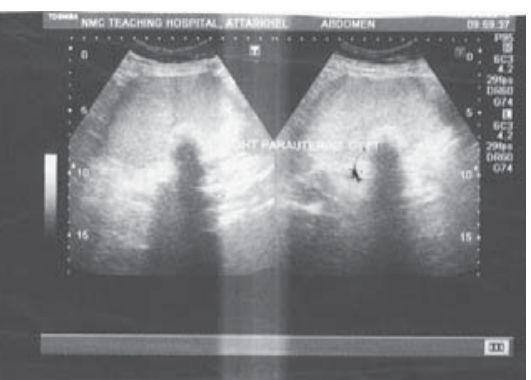

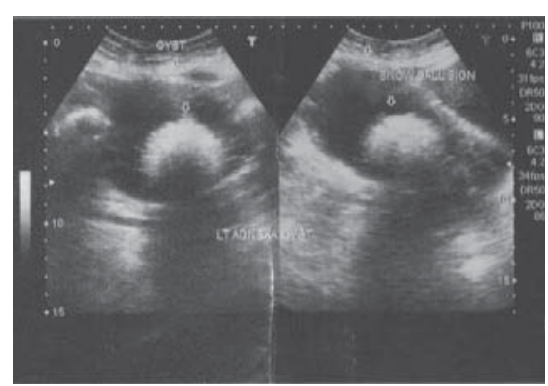

Figure 22: Adipose material showing white ball or snow ball sign of dermoid cyst. 
In 1998 Patel et al described the following ultrasonographic features as being specific for dermoid cyst: (a) The presence of an echogenicity with acoustic shadow, (b) diffuse or regional shining echoes, (c) hyperechoic lines and dots, and (d) the presence of fluid-fluid level ${ }^{20}$. He demonstrated that about $3 / 4$ of the dermoid cysts show at least two of the above characteristics, while no other adnexal mass presents more than one of these features. So the presence of the two characteristics indicates a positive predictive value of $100 \%{ }^{20}$. Transvaginal ultrasonography has an established role in the evaluation of adnexal masses, and provides an accurate assessment of ovarian morphology. Mais et al consider that mature cystic teratomas may be diagnosed by endovaginal ultrasonography with a $99 \%$ specificity and only a $50 \%$ sensitivity ${ }^{15,27}$. Although Benacerref et al $^{34}$ reported a $15 \%$ failure rate in differentiation of benign and malignant cysts during transvaginal ultrasonographic diagnosis of complicated cysts but histologic results revealed the accurate benign diagnosis in $97 \%$ of the cases.

About two third of the dermoid cysts are usually easy to recognize on ultrasound because of the polymorphic aspects of complex masses that consists of both hyperechoic and hypoechoic components ${ }^{12}$. Most teratomas (about 65\%) contain extremely intense echogenicity. No other tumour has this feature ${ }^{28}$. Around $10-15 \%$ of the cystic teratomas are entirely echoic without intense hyperechoic structure ${ }^{28}$. Another $10-15 \%$ of the dermoid cysts are anechoic or shows a predominantly cystic pattern and cannot be easily differentiated from other cystic masses (Figure 21) ${ }^{27}$. Even transonic lesions contain parietal nodules on the histopathological analysis, but sometimes these nodules are too small (under three to four $\mathrm{mm}$ ) to be detected ultrasonographically. Also, even if the cyst has a mixed content, the absence of a significant interface between sebum and fluid may present the explanation of purely transonic appearance ${ }^{13}$.

\section{CONCLUSION}

Mature cystic teratomas or dermoid cysts present various and complex ultrasonographic aspects making diagnosis difficult and lead to confusion. By being attuned to certain characteristics features, however, an ultrasonologist may be able to make a diagnosis with confidence, even when the nature and location of the mass is extremely unusual.

\section{REFERENCES}

1. Talerman A. Germ cell tumors of the ovary. In: Kumar RJ, editor. Blaustein's pathology of the female genital tract. 4th ed. NY: Springer-verlag; 1994. p. 849-914.

2. Whitecar MP, Turner S, Higby MK. Adnexal masses in Pregnancy: a review of 130 cases undergoing surgical management. Am J Obstet Gynecol. 1999;181:19-24.

3. Linder D, McCaw BK, Hecth F. Parthenogenic origin of benign ovarian teratomas. N Eng J Med. 1975;292:63-6.

4. Outwater EK, Siegelman ES, Hunt JL. Ovarian teratomas: tumor types and imaging characteristics. Radiographics. 2001;21:475-90.

5. Matz NH. Benign cystic teratomas of the ovary. Obstet Gynecol Surv. 1961;16:591-605.

6. Comerci JT Jr, Ucciardi F, Bergh PA, Gregoric C, Breen JL. Mature cystic teratoma: a clinicopathological evaluation of 517 cases and review of literature. Obstet Gynecol. 1994;84:22-8.

7. Hasanzacheh M, Tabare S, MLrzean S. Ovarian dermoid cyst. Professional Med J. 2010;17(3):512-5.

8. Canis M, Mage G, Pouly IL, Wattiez A, Manhes H, Bruhat MA. Laparoscopic diagnosis of adnexal cyst mass: a 12 year experience with long term follow up. Obstet Gynecol. 1994;83:707-12.

9. Brown MF, Herba A, Mcgeehin K, Ross MJ. Ovarian masses in children: a review of 91 cases of malignant and benign masses. J Pediatr Surg. 1993;28:930-3.

10. Alanbay I, Coksuer H, Erean M, Karasahin E, Keskin $\mathrm{U}$, Basar I. Multiple recurrent mature cystic teratoma of the same ovary: case report and literature review. Med J Kotatepe. 2011;12:8-12.

11. Caspi $B, A$ ppelman $Z$, Robinerson D, Zatel $Y$, Tulandi $T$, Shoham Z. The growth pattern of ovarian dermoid cysts. A prospective study in premenopausal and postmenopausal women. Fertil Steril. 1997;68:5015.

12. Sisler CL, Sigel MJ. Ovarian teratoma: a comparison of the sonographic appearance in prepubertal and postpubertal girls. Am J Roentgenol. 1990;154:13941.

13. Fleischer AC, Entman SS. Sonography evaluation of pelvic masses with transabdominal and/or transvaginal sonography. In: Flieschar AC, Manning FA, Jeanty $P$, Romero $R$, editors. Sonography in Obstetrics and Gynecology. Principles and Practice. 6th ed. McGraw-Hill; 2001. p. 883-911.

14. Valentin I. Pattern recognition of pelvic mass by gray-scale ultrasound imaging: The contribution of Doppler ultrasound. Ultrasound Obstet Gynecol. 1999;14:338-47. 
15. Hoo WI, Yazbek J, Holland T, Mavrelos D, Tong ENC, Jurkovic D. Expectant management of ultrasonically diagnosed ovarian dermoid cysts: Is it possible to predict outcome? Ultrasound Obstet Gynecol. 2010;36:235-40.

16. Jermy K, Luise $C$, Bourne $\mathrm{TH}$. The characterization of common ovarian cysts in premenopausal women. Ultrasound Obstet Gynecol. 2001;17:140-4.

17. Moyle JW, Rochester D, Sider T, Shrock K, Krause P. Songraphy of ovarian tumors: Predictability of tumor type. Am J Roentgenol. 1983;141:985-91.

18. Anteby E Y, Ron M, Revel A, Shimonovitz S, Ariel I, Hurunitz A. Germ cell tumours of the ovary arising after dermoid cyst resection: a long term follow up study. Obstet Gynecol. 1994;83(4):605-8.

19. Westhoff C, Pike M, Messey M. Benign ovarian teratomas: a population-based case-control study. Br J Cancer. 1988;58:93-8.

20. Patel ND, Feldstein VA, Lipson SD, Chen DC, Filly RA. Cystic teratomas of the ovary: diagnostic value of sonography. Am J Roentgenol. 1998;171:1061-5.

21. Allam-Nandyala P, Buim M, Caracciolo $T T$, Hakam A. Squamous cell carcinoma and osteosarcoma arising from a dermoid cyst- a case report and review of literature. Int J Clin Pathol. 2010;3(3):313-8.

22. Peterson WF. Malignant degeneration of benign cystic teratoma of the ovary. Collective review of literature. Obstet Gynecol; 1957;12:793-830.

23. Chapron C, Dubuisson JB, Samour N, Fouwt H, Aubriot FX, Amsqer $\mathrm{Y}$, Morice P. Treatment of ovarian dermoid cysts. Place and Modalities of Operative Laparoscopy. Surg Endosc. 1994;8:10925.
24. Gallion $\mathrm{H}$, Van Nagell JR, Donaldson ES, Hanson MB, Powell DF. Immature teratoma of the ovary. Am J Obstet Gynecol. 1983;146:361-5.

25. Kocak M, Dilbaz B, Ozturk N, Dede S, Atlay M, Dilbaz $S$, et al. Laparoscopic management of ovarian dermoid cysts: a review of 47 cases. Ann Saudi Med. 2004;24(5):357-60.

26. Hurwitz JL, Fenton A, McCluggope WG, McKenna S. Squamous cell carcinoma in a dermoid cyst of the ovary, a case series. Br J Obstet Gynaecol. 2007; 114:1283-7.

27. Mias V, Guerriero S, Jossa A. Transvaginal Sonography in the diagnosis of cystic teratoma. Obstet Gynecol. 1995;85:48-52.

28. Cálin M. Ovarian dermoid cysts: Ultrasonographic findings. Medical Ultrasonography. 2009;11:4:61-6.

29. Quinn SF, EricksonS, Black WC: Cystic ovarian teratomas: the sonographic appearance of the dermoid plug. Radiology. 1985;155:477-8.

30. Sheth S, Fishman EK, Buck JL, Hamper UM, Sanders RC. The variable sonographic appearances of ovarian teratomas: Correlation with CT. Am J Roengenol. 1988;151:331-4.

31. Surratt JT, Seigel MJ. Imaging of paediatric ovarian masses. Radiograph. 1991;11:533-48.

32. Kawamoto S, Sato K, Matsumoto H. Multiple mobile spherules in mature cystic teratoma of the ovary. Am J Roentgenol. 2001;176:1455-7.

33. Buy JN, Ghossain MA, Moss AA. Cystic teratoma of the ovary: CT detection. Radiology. 1989;171:697701.

34. Benacerraf B, Finkler N, Wojceichowski C, Knapp R. Sonographic accuracy in the diagnosis of ovarian masses. J Reprod Med. 1990;35:491-5. 